\title{
The significance of distance constraints in peasant farming systems with special reference to sub-Saharan Africa
}

\author{
M. K. McCall \\ Technology and Development Group, Twente University of Technology, \\ PO Box 217, 7500 AE Enschede, The Netherlands
}

\begin{abstract}
Analysis of agricultural development potential at village level tends to neglect the factor of relative location, compared with the attention paid to physical resources and economic factors. This paper argues that, in African peasant agriculture, distance takes on increasing significance when farming populations are resettled and agglomerated, there being little intensification in evidence. The impacts of agglomeration and excessive 'journeys to work' are identified as affecting the quantity and the quality of agricultural labour inputs, the collection of domestic necessities (especially fuelwood), livestock husbandry, and socio-cultural and welfare conditions.

Some simple analyses of time-distance relations, such as the "effective working day', are also described, and a model of peasant decision-making with respect to optimizing farm activity location is proposed as a descriptive-explanatory tool. Response to distance problems is considered as part of rural change; and the particular position of peasant women vis- $\grave{a}$-vis distance and transport technology is stressed. Data collection methods and descriptive statements of the spatial relationships within a village, or an agro-ecological zone, are outlined within the framework of rapid rural appraisal. Finally, a number of potential solutions to the agro-economic distance problem are briefly discussed-either as changes in farming systems, or as redistributions of the working population. Changes with the greatest potential are intensification and satellite settlements, though both face difficulties in policy and in implementation.
\end{abstract}

\section{Introduction}

Agricultural development practitioners increasingly make use of a 'farming systems' (FS) framework for the comprehensive understanding of peasant agriculture in a particular area. The conceptual features of the FS methodology have already been developed-the systems approach, identifying key problem areas through sequential sieving, multistage information acquisition through rapid appraisals and detailed verification surveys, employing indigenous knowledge, etc.-as described for example in Byerlee et al. (1980), Collinson (1982), Raintree (1984), and ICRAF (1983).

However, the FS object of interest, which is 'the totality of production and consumption decisions of the farm-household', is frequently deficient. Although significant attention is paid to socioeconomic structure, and emphasis is given to the temporal dynamics of peasant decision-making in response to external economic changes and to environmental variability, relatively little attention is paid to the factor of location (i.e. the spatial adjustments of farmers to their environmental and 
time resources). Relative location of fields and home sites is not always a highly significant factor, as compared with pricing policy, government campaigns or climatic uncertainty, but adjustment to distance does have an additional effect on cropping choices, livestock integration and the intensity of inputs. Although this paper is addressed primarily to farming systems of sub-Saharan Africa, the argument is applicable to other systems characterized by relatively low intensity of land utilization, dominance of hand tools, dependence on climate and weather, and, less restrictively, by a high proportion of female labour.

\section{Locational decisions for peasant farmers}

A basic determinant of spatial patterns of agriculture is the physical effort involved in the 'journey to work'. Therefore, any locational choice within a farming system is a function of time, distance and resource constraints. These include: the distance from homesite to different fields; the modes of transport to the fields; the frequency of labour inputs and seasonal peaks in cultivation; the bulk and frequency of inputs; the crop protection needed; the bulk and timing of harvested crops; and the integrative effects of multicropping and crop-livestock or agroforestry combinations. Economies of scale are an additional constraint on the location of farm activities; but though they are in part supplementary to the distance factor, they are also due to other efficiencies, particularly the potential for division of labour and specialization.

The local decisions may appear at two levels. Firstly, they occur in the selection of farm enterprises for plots at locations relative to the home site; that is, the best allocation of labour effort in different fields, as well as for fuel, water and so on. Secondly, they emerge in the selection of the home site relative to fixed locations of resources of water, grassland, wood or differential soil qualities. This problem also appears at other scales (e.g. location of villages, markets or agricentres).

In industrializing countries the relative importance of the journey to agricultural work and movement costs is declining due to a combination of technical improvements in transportation and a rapid increase in scale and uniformity in the farming landscape. However, in many parts of tropical Africa the problem of spatial accessibility to farmland is being exacerbated by the rapidly growing rural populations with a high proportion of non-productive dependants. This is aggravated by the situation of women being the main providers of water and fuelwood, commonly performing longer field hours than men, and being less likely to have access to transport. Additionally, there is environmental deterioration near to population concentrations, including the destruction of fuelwood resources. This is in part due to the generally slow rate of land-use intensification compared to the increasing population and declining natural fertility. Indirectly, government policies for export or cash crops which enforce minimum acreages or levels of state procurements add to the overall accessibility problem. Government policies of resettlement and rural consolidation (e.g. in Tanzania, Zimbabwe, Ethiopia, Somalia and Mozambique) often worsen the situation; though generalization is difficult because the different settlement strategies reflect a variety of state goals, including efficient farming, improved social services and increased state control over surplus.

\section{Population aggregation strategies}

Resettlement strategies introduce trade-offs between, on the one hand, the scaleeconomy and transport benefits from providing primary services, goods and 
administration to population aggregations, and, on the other hand, the tripfrequency and intensity-related transport costs for individual farming. The tradeoffs are between the two sets of trips: 'external economy' to home site, and home site to fields. Policy-makers and rural planners should therefore consider the following aspects of aggregated settlements vis-à-vis dispersed home sites:

1. The frequency of the kinds of trips. Home site to field trips range from 150 to over 400 per year, depending on the farming system, whereas trips to central services would rarely be over 150 , and probably below 100, with the exception of children's school trips which may exceed 800 per household per annum. Trips to a grain mill are normally 70 a year. Water is usually collected twice a day and fuelwood one or two times a week.

2. The aggregate loads carried to/from fields (subsistence food and market crops) will generally be more than the loads between village and home site (some farm inputs, purchased commodities like sugar, kerosene, rice, and sometimes sick children).

3. The 'significance' of movements as a measure of the degree of urgency or necessity will depend on the cropping system and the response of crops to growing conditions and their vulnerability to hazards. On the other hand the cost of delays in reaching distant service centres must be considered, especially for health services.

4. There are fixed costs of developing and maintaining marketing and service infrastructure. This varies with the number and capacity of the service centres (clinics, schools, shops, vet centres, etc.). The possibilities of mobile periodic services should also be examined.

5. The peasant has direct control over home site-field transport (i.e. leg power) but much less over external world-village transport. In practice this often results in delays and inefficiencies in receiving inputs and evacuating products.

6. National policies regarding the priorities of productive activities versus provision of social services to rural people should be considered.

\section{Effects of spatial inaccessibility on peasant farming}

The degree to which excessive home site-field distances hinder peasant farming depends on the history of the farming system-to what extent farming has adapted to longer trips to the point of production either through intensification or modified travel patterns. The problems discussed below are most true of dramatic or rapid changes in settlement and land use patterns or in the carrying capacity of the land; that is, in zones of population growth in a restricted area with few opportunities for long-term adaptation. Examples are areas of rapid population influx due to resettlement schemes, villagization or refugee settlement, or sudden restrictions on land availability such as land alienation for plantations or state farms. Problems also exist, though less seriously, in areas of sustained but gradual growth rates where there has been more time to adjust.

Access problems are also caused by high levels of land fragmentation where average home site-plot distances may be small but aggregate travel per season may be very high. However land fragmentation is not considered separately here since its travel aspects are subsumed within the general distance problem. Fragmentation does not necessarily mean that farmers are forced to use distant plots; intensity adjustments are usually feasible such that farmers can work their nearer fields most intensively - that is, they can locate there those activities requiring the most labour- 
hours, and thus, most trips per season. King and Burton (1982) discuss this further (see also Chisholm 1979). Nevertheless, nucleated settlements are more likely than scattered homesteads to experience land fragmentation, as has been shown for Uganda by Tindituuza and Kateete (1971). This is presumably due to more persistent processes of inheritance, indebtedness, litigation and land redistribution, coupled with fewer possibilities of relocating in low density zones.

Numerous aspects of these access problems can be distinguished:

1. Distance to fields clearly has effects on labour input and productivity and thus on yields and total production. Walking say $4 \mathrm{~km}$ to a plot reduces fieldwork time by about 25 per cent (even assuming a generous eight-hour day). Many farmers in large villages walk longer distances than that, especially to grazing land, and sometimes to special-quality land. Chisholm (1979) marshalled considerable evidence on differences in labour and other inputs with distance from the home site, the corresponding variations in levels of returns, and thus differences in the farming activities selected. Reduced labour intensity and the choice of crop are the salient effects of the journey-to-field problem, of which Chisholm provides numerous examples, mainly from West Africa (1979: 54-56); for instance assessing that intensive cultivation tends to drop off beyond 2 to $4 \mathrm{~km}$ (i.e. one hour's walk). The following brief points however identify some further effects.

2. Apart from the labour intensity (person-hours per season) being reduced, the quality of the labour input (i.e. the care, attention, 'quality control') also suffers because of the extra weariness and the need to perform most of the labour during the midday heat. (See discussion on 'time-use intensification' in Carlstein 1982: $349 \mathrm{ff}$.)

3. Maximum head loads for peasant farmers-men and women-are typically $25-40 \mathrm{~kg}$, depending on the distance and the type of load; though women carrying over $60 \mathrm{~kg}$ of firewood are not unrecorded. Only light loads of inputs or bulky harvested crops can be carried over long distances and thus more trips would have to be made for a given agricultural activity; so, for example, the use of manure on distance cotton fields is impossible at a recommended seven tons per acre.

4. Protection of pre-harvest crops against wandering livestock, monkeys, pigs, birds and other vermin is very difficult on distant fields. Human theft of standing crops is similarly harder to prevent. Peasants may be forced to stay up to 4 to 6 weeks in distant temporary shelters to guard their crops. This causes problems for the food supply, and problems of health and social dislocation for the household members remaining in the village if one or more of the adults is absent.

5. Generally, yields under these conditions are reduced by poorer husbandry, especially less weeding, and less careful harvests. Weeding around tree crops may be replaced by burning weeds, with possibly disastrous consequences for the trees and even settlements; this happened with distant cashewnut holdings after villagization in parts of coastal Tanzania (Ellis 1981).

6. Female peasants face an especially problematic situation. They have less time available for domestic household reproduction activities, child care, food storage and its preservation and preparation, domestic cleaning, collecting water and fuelwood, and for carefully tending cooking fires. (There is also less time for traditional male domestic tasks such as house building and socializing.) Lowprotein and uncooked foods can become a more common element in peasant diets (Tinker 1980). Moreover, in general, female peasants perform more than a 
proportional share of field labour, and most of the headloading to/from fields; for example, a Kenya survey found over 80 per cent of field headloading was by women (Carr 1983) (see Tables 1 and 2).

7. The settlement pattern also affects resource availabilities. Agglomerated settlements result in better access to water supplies where the government gives these a high priority, but much more severe problems with fuelwood. Long walking distances to remaining bushland or natural forest are a burden falling primarily on women, who have the responsibility for domestic fuel collection. This, together with accelerated depletion of wood supplies and its consequences, is a widely-known effect of population concentration (see e.g. Hoskins 1980; Cecelski 1984).

8. Longer distances to grazing land and water points are usually found in the dry season which inhibits livestock growth and yields and places heavier demands on herding manpower. Larger households cope more easily because they can spare young males for long treks; small herds must graze closer to home. In the vicinity of large villages there is more conflict between agriculturalists and pastoralists because of damage to standing crops, water source pollution, gullying along tracks, destruction of hedges and so on. The settlement of pastoralists has been treated in detail in O'Keefe and Wisner (1977) with case studies from Sudan and Kenya (see also Toulmin 1983).

9. Reduced access to land within easy walking distance means the reduction or elimination of fallowing, with natural consequences, as well as increased erosion and soil loss. Moreover, any marginal lands on steep slopes or poor soils which are easily accessible will be exploited probably without protective measures. More distant formerly cultivated areas may revert to scrub and tsetse bush. Furthermore, limited accessible land and declining fertility tends to increase dependence on high-yielding, low-nutrition foods like cassava, sweet potatoes and bananas, adding to the poverty-nutrition cycle of agricultural involution (Ruthenberg 1976).

10. Distant landholdings can become concentrated in the hands of richer peasants who own tractors, pick-ups or ox-carts. A local land shortage can provoke land disputes and general social insecurity, and increases in witchcraft and witchhunting are common manifestations of this: viz. social differences between settled and mobile peoples in dealing with conflicts (Monod 1975).

11. If the distance problem arises suddenly, perennial and tree crops formerly grown may be abandoned when farmers move to new settlements. This was the case for cashewnuts, oil palms, castor seed and fuelwood trees, among others, after the Tanzanian villagization of 1973-5 (McCall 1983).

12. Resettlement is usually associated with land consolidation and regulation which tend to operate against traditional female rights by registering land in the name of the 'head of household', who almost invariably is declared to be male. Women lose an independence they may have held in principle, and often in practice, to build separate homes or cultivate their own plots and to hold direct inheritance (see Hahn 1982; Tadesse 1982).

Where deliberate resettlement has taken place, the deleterious effects of long distances to fields might be countered by the positive benefits of agglomeration. However, these benefits-such as the potential for intensification, land consolidation, better access to services, new income-generating activities, and improved marketing-are dependent on a certain degree of concurrent changes in the conditions of production. Historical experience is that the necessary capital invest- 
ment, institutional innovations and social reorganization rarely take place concurrently, so that, in effect, the organization of farming retains its previous characteristics, only with greater distances to overcome.

\section{Modelling peasant land utilization-location decisions}

In as much as peasants are in a position to make a choice in allocating activities to different plots, their decisions can be considered as being a function of the yield and gross returns, the number of man-days labour input, the distance to the plot (thus the effective working day), movement costs, peak labour conflicts and other farming system interrelationships. As far as these factors can be quantified, farmers would choose to grow that crop which gives the highest 'location rent' (net returns) at the particular location.

The expression below is not easy to quantify but is intended to reflect the logic by which peasant farmers allocate land utilization to plots; that is, based on the labour requirements and expected returns. There are other significant factors which ought also to be incorporated here, especially attitudes towards risk, seasonality constraints, and non-monetary returns from 'subsistence' activities (cf. Jackson 1972; Doyle 1974). This approach is aimed above and beyond the bare subsistence requirements of households; but there is no simple distinction between 'food crops' and 'cash crops' in most African farming, and with increasing commercialization, food is often purchased with income earned from farming.

The expression is based on the von Thünen model of agricultural location of 19thcentury classical economics. (For a clear introduction and applications, see Chisholm 1979). In the von Thünen formulation, location rent, $E$ is given by:

$$
E=y(p-c)-y t d
$$

where $y=$ yield, $p=$ market price, $c=$ production costs per unit, $d=$ distance to market, and $t=$ unit transport cost.

The modified expression is:

$$
R=y(p-c)-\left(2 t d n+t^{\prime} d y / h\right)
$$

where $R=$ the location rent for a specific crop, crop combination or crop sequence at a particular location $\left(\$ \mathrm{ha}^{-1}\right)$

$y=$ the yield which is site-specific due to growing conditions $\left(\mathrm{kgha}^{-1}\right)$

$p=$ the price received at the buying centre (thus it could take into account any cost of transport from the home site to the buying centre) $\left(\$ \mathrm{~kg}^{-1}\right)$

$c=$ the production cost of the crop or combination which is site-specific due to physical conditions $\left(\$ \mathrm{~kg}^{-1}\right)$

$t=$ the unit cost of movement to the plot $\left(\$ \mathrm{~km}^{-1}\right)$

$d=$ the travel distance to the plot $(\mathrm{km})$

$n=$ the number of field days of labour for that crop (i.e. the number of round trips per hectare per season to that plot)

$t^{\prime}=$ the unit cost of transporting back the harvested crop (usually by headloading) $\left(\$ \mathrm{~km}^{-1}\right)$

$h=$ the (maximum) weight carried on each trip, say $30 \mathrm{~kg}$ if headloading $(\mathrm{kg})$.* $^{*}$

*1. 'Rents' would be specific to intercrops and multicrops, as well as for pure crop stands.

2. Poor environmental locations would tend to have both lower yields and higher production costs in terms of inputs, which farmers are assumed to be well aware of. 


\section{The 'effective working day' and cropping decisions}

The labour constraint, equivalent to the number, $N$, of necessary trips to the plot, is location specific. Approximate requirements for growing crops can be calculated in man-days per hectare, but the effective working day in the field is limited by the distance. Thus:

$$
n=M / E w d
$$

where $M=$ the theoretical 'man-equivalent' days per hectare for a particular crop

$E w d=$ the effective working day expressed as a proportion of a standard working day.

In practice, farmers would not make so many additional trips to counteract a short effective working day, because there is always some slack in the system (the farmers can work harder or take fewer breaks); or they can easily stay a bit longer in the field; or, most likely, they will simply exercise less care in weeding and harvesting and thus reduce labour quality. On the other hand, lower quality implies lower yields, which for the long-run crop decision is equivalent to more days in the field. Moreover, there is probably a marginally increasing aversion to increasing the number of field-days. But, overall, we can approximate the relationship between $n$ and $E w d$ as linear.

Due to labour bottlenecks there are absolute limits on farming activities at longer distances, in addition to the increase in the number of long trips. If the $E w d$ is very short, the number of necessary field-days for crop activities can be too many for the family labour force to supply, taking into account other farm work needed at other locations and necessary subsistence activities. Thus there is a threshold, limiting certain farm activities beyond a certain distance. The problem may not appear over the whole season but arise only during peak labour periods when activities must be performed urgently.

If the $E w d$ is very short, a theoretical solution would be to cultivate a smaller area. In the model above, such a solution might still give the highest location rent for a small part of the distant plot. However, in reality, economies of scale would work against using very small distant subplots (King and Burton 1982: 483). Therefore, to exclude such a possibility within the model, minimum feasible areas of activity at different distances could be specified. These would be proportional both to the value $M$ for a particular crop system, and to the $E w d$ at different plot distances.

There is more than just academic utility in modelling peasant allocation procedures in von Thünen terms. It emphasizes the underlying economic rationality of peasant decision-making and land-use allocation which is mainly determined by official markets and private trading opportunities. The allocation parameters are, of course, very limited by the needs of domestic consumption (Jackson 1972) and by the necessary, sometimes enforced, production of surplus for the state. However, what degree of choice remains is largely explained by the cost-benefit relationship summarized as location rent. For planning, the method helps to isolate seemingly irrational allocations and to identify trends and potential bottlenecks in production.

3. In a detailed analysis, production costs should include any necessary provision of water to a particular plot, since water input is often the limiting constraint in tropical agriculture.

4. Movement costs of people, $t$, could be assumed to be linear and related to the value placed on time, whether spent in 'leisure' or in directly productive activity. Valuing time is problematic, especially with regard to peasant women-should their inputs be valorized in terms of cash-earning ability, other farm productive activities, or also their necessary 'subsistence' activities (see e.g. Beneria, 1982)?

5. Movement costs in reality are likely to be marginally decreasing with distance. $t$ also depends on the mode-pack animals, bicycles, carts-and for headloading, on which household members perform it. 
The focus on spatial relations does not detract from the farmers' problems of allocating labour over time. Indeed, allocations of land, labour and other resources over space and over time are complementary, as is clearly spelt out in Carlstein's (1982) survey of space-time relations.

\section{Intensity of farming practice and quality of labour input}

Peasant farming is far from a homogeneous enterprise, even considering specific crop production systems. Farm management studies consistently show enormous variation in output, yields and crop quality, which are not solely dependent on factor endowments or quantitative labour inputs. The causes lie in the qualitative variations in crop and livestock husbandry-in the levels of care and management. (Such differences are even more noticeable for owner-farmers vis-di-vis hired labourers.)

Although the situation is clearly recognized by field agronomists, the qualitative causes are rarely examined systematically. It is very difficult to isolate and quantify the differences in behaviour, and explanations tend to be couched in psychological or cultural terms. Therefore, despite accounting for up to two-thirds of differences in gross output (Young and Goldsmith 1977; also, Shapiro 1982/3), the 'quality of work' factor is played down in farm management studies. No new methodology is offered here, but it is reiterated that such differences in intensity will be even more marked where fields are distant. Longer journeys imply more time and more effort before work begins, shorter field hours mean faster and probably less careful work which deteriorates during the day, and more fieldwork has to fall in the hottest periods, often without a food break. Yield-improving husbandry measures will be drastically reduced, performed sloppily, or even curtailed, in order to cover sufficient area in the short time available.

The relevant measures depend on the specific farming system; but performance data which could be collected to examine the effects of distance on 'quality' might include: tie-ridging and other intensive forms of land preparation; the number of weedings and the method used; field examination for insect pests and crop disease; the number of applications of insecticide or of fertilizer; the amount of bird-scaring; the comprehensiveness of harvesting; care with herding to avoid damage to crops; the examination and care of sick animals; husbandry of pack and draught animals; and the examination and maintenance of equipment. Larger-scale measures, which are easier to assess, include introducing contour ridging and planting wind-breaks or fuelwood lots.

\section{The particular position of women}

It is well documented that in African peasant agriculture women perform the large majority of domestic activities, most of the food crop production activities, and contribute a good share of cash crop labour, though there are regional variations to this generalization. Female labour availability in terms of quantity, seasonality, location, labour quality and incentives, is therefore the key to agricultural improvement. Furthermore, any deterioration in local ecological or health conditions will affect women (and children) first, the usual situation being that if food is scarce men will have first consumption (cf. Cecelski 1984). Therefore any environmental change, due inter alia to altered spatial patterns, will translate first into women's agricultural activities.

The transport of water and biomass fuel is almost exclusively undertaken by women, as is also the movement of harvested crops from the fields. The exceptions 
Table 1. African women's participation in labour activities: general situation

Percentage of work performed by women

\section{Production activities}

Cash crop production

Food production

Food processing

Animal husbandry

Marketing

Brewing

Water collection

Fuel collection

Transport crops from field

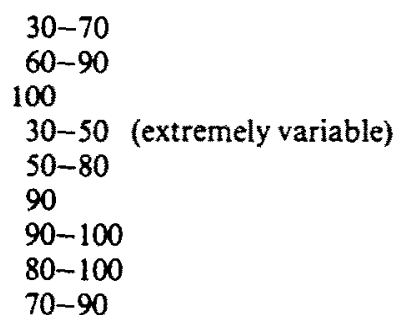

\section{Household/community activities}

Rearing and care of small children

100

100

100

Cleaning, washing, etc.

House building and repair

$30-60$

$50-80$

50

$10-20$

$10-25$

Socializing-dances, funerals, weddings, etc.

Litigation activities

Political meetings, etc.

Note: These are very crude approximations based on published and unpublished surveys; see especially Blumberg (1981) quoting UN sources.

Table 2. African women's participation in labour activities: a detailed case from Bukoba District Tanzania

\begin{tabular}{lcc}
\hline & $\begin{array}{c}\text { Average male input } \\
\text { (Hours per adult household member per 14-hour day) }\end{array}$ \\
\hline Total on-farm work & $3 \cdot 10$ & $4 \cdot 37$ \\
$\begin{array}{l}\text { Domestic (food preparation, } \\
\text { wood, water, child care, etc.) }\end{array}$ & $1 \cdot 16$ & $3 \cdot 37$ \\
Total work-including & & $7 \cdot 90$ \\
$\quad$ paid employment & $6 \cdot 44$ & $3 \cdot 41$ \\
\hline
\end{tabular}

Source: Adapted from Kamuzora (1984)

are usually where improved means of goods transport have been introduced in the form of pack animals such as donkeys, ox-sleds or tractors. Men's share of transport is then increased but with little extra physical effort. The burden on women and girls of rural transport needs is thus twofold: they already have a disproportionately high workload in other economic sectors (both market and household oriented) which is cut into when distances and transport needs become excessive; and most of their transport efforts are of very low efficiency (i.e. simple head-loading). The realities of head-loading are also reflected in the high incidence of injuries from falls and chronic back and muscular pains suffered by many peasant women (Carr 1983). When labour-reducing transport technology is introduced it will probably be outside 
women's control and though it may reduce some of the porterage, they still face long walking distances for increased field labour. Furthermore, women's foodcrop fields may be located farther away from the village than men's cashcrops, as has been reported for the Gambia, and for Kigezi, Uganda (Tindituuza and Kateete 1971). Jackson (1970) found in Southern Ethiopia similar differential locations of richer and poorer peasants' plots.

\section{Examining changes in the farming system over time}

Adaptation to spatial parameters, as to socioeconomic conditions, is the result of historical conditions and of externally or internally induced changes, and therefore shows lags in adjustment. Recent changes in land utilization, marketing, population, and so on are vital to an understanding of the present rationality of farming behaviour and probable future trends. What a researcher might view as a key management problem may be actually a brief lag in response to external changes, or a temporary delay whilst local farmers await possible further changes in their environment.

The significance of 'response to distance' will be demonstrated by locational changes over time, in particular, by: changes in crop patterns and land utilization at different distances; changes in cropping intensities, multi- or mono-cropping, or seasonality of work inputs; and by changes in transporting bulky harvest and inputs -perhaps a switch to donkeys, ox-carts or bicycles.

Changes in the livestock system could be expressed as adjustments in grazing and watering patterns in the diurnal cycle, or a switch to transhumance; the (male) agegroups which can be spared for herding; an increase in draught animals; or a reduction in ox-ploughing because animals are absent or weakcr.

There are likely to be changes in the settlement patterns-e.g. to more permanent or more temporary shelters; or adolescent males may no longer be able to acquire their own huts or plots.

Changes in domestic subsistence activities are primarily the result of time pressure on women. Significant effects are found on the frequency, duration and labour inputs to collecting water and fuel (as well as in the social organization of their collection), reduced time for food preservation and cooking and in time devoted to children. In addition, a check can be made with health and nutrition surveys for changes in infant mortality, child malnutrition and intestinal diseases which may be related to reduced hygiene and food care.

Changes in the social activities needed for maintaining peasant relations of reciprocity, tributes and redistribution to dependants (e.g. dances, beer parties, marriage and funeral ceremonies) also follow from land pressure and distance problems. Local beer is a good measure of the significance of change. In most rural Africa, except where there are strong religious sanctions, the pombe* economy is highly significant in the local farming system. Saul (1981) provides a detailed analysis of dolo production and consumption in Upper Volta and there are briefer accounts from other countries such as Zambia (Hedlund and Lundahl 1984) and Tanzania (McCall 1985). A prodigious quantity of grains or other foods are converted into beer -a study quoted by Saul (1981: 747) estimated that 50 per cent of the grain consumed by Ouagadougou households was converted into dolo. Due to this and to the high

\footnotetext{
* Pombe, the term generally used in eastern Africa, is Kiswahili for beer locally brewed from grains, especially sorghum or maize varieties, -dolo in francophone West Africa.
} 
level of demand, crops such as finger millet or bananas, which are locally preferred sources of malt, become important traded cash crops so that beer production and consumption generate significant cash flows in the rural economy. Brewing provides cash employment for some rural women, and is a prime means for women to obtain cash for expenditure on children and household; this money is largely recycled cashcrop earnings which the female producers (in part) laboured for, but the male "heads of households' sold in the market.

Brewing is a considerable-and inefficient-consumer of fuelwood, accounting for about 15 per cent of annual consumption in sample Tanzanian villages and thus adding to the ecological pressures. Whereas beer-drinking can be a direct cause of low labour productivity, it can also provide considerable calories and vitamins to supplement adult (particulary male) diets. The increasing demand and the diversion of labour and resources from food production to brewing thus reflect the commercialization and changes in resource and time allocations resulting from population aggregation.

\section{The distance factor in farming systems planning}

In most farming systems literature the spatial organization of peasant agriculture is accorded a low priority relative to that given to physical resources, labour organization and market constraints. The best-developed methodology for farming systems research-from CIMMYT (see Byerlee et al. 1980; Collinson 1982)-incorporates information on spatial structure only as part of the review of the underlying economic and environmental conditions. In their 'exploratory survey' stage, spatial organization is not explicitly mentioned, although subsequent management strategies would depend on relative location; whilst the later 'verification survey' emphasizes 'system interactions' in the key farming problem areas but without stressing that system interactions are actually very sensitive to changes in spatial organization. As examples, changing intensity of labour inputs, changes in crop-livestock combinations, expanded capital inputs such as irrigation, and external changes in relative prices would all induce spatial adjustments of varying degrees.

In planning farming systems improvements, distance to fields should be taken as a constraint on the alternatives considered; and similarly, spatial reorganization and movement improvements should be included among the potential solutions examined.

\section{Rapid data collection and descriptive methods for distance problems}

How can information on local spatial problems be collected within the scope of rapid appraisal in a village or farming systems zone? A first impression can best be provided by a sketch map showing relative locations of settlements and types (or groups) of farms. Byerlee et al. (1980) recommend 1:50000 sheets to define the FS area and as fieldwork frames; these would often be sufficient to highlight relative location, depending on factors such as the amount of variability within the farming system and the extent to which agriculture is a communal activity. Maps should also serve as a basis for delineating the spatial conditions of production, marketing and consumption. Whether the maps should be of a village or of individual farms also depends on the local farming system.

Within the village the different groups or classes with differential access to land should be distinguished. Three aspects of differentiating access to land can be found: 
1. the total acreage available to the farmer including land borrowed, leased or shared;

2. the quality of the land; after land reform a more equitable distribution of acreage may be found, but with big quality differences between, for example, individuals with watered valley-bottom sites and those with less fertile interfluve sites;

3. the location of the plots relative to home site, input services and marketing channels.

Sketch maps could also be made of the land units in a specific area or representative village. The 'land units' can be based on distinct land facets which are combined into land systems utilizing topographical, hydrological and soil information from reconnaissance-level surveys. The land units might also be delineated in terms of land utilization and farm production systems, based on rapid surveys and indigenous knowledge (Vink 1983). The purpose is primarily to illustrate how in practice land units are related both to physical resource characteristics and to historical land utilization; and therefore to demonstrate the rational adaptation of peasant farmers to soil catenas and drainage for example, as well as to accessibility. The output is also investigative and programmatic, in that it can highlight apparently non-rational land use and explain it. Additionally it can identify key management and planning bottlenecks in the farming system.

Village sketch maps should also be drawn to point out areas of unequal resource access due to social relations of production. These might include land alienated to state or parastatal holdings, and to large-scale private plantations or forests. They should further include 'traditional' land rights, such as grazing access restricted to specific subclasses or clans, 'traditional' common land which could remain open access, and land currently preserved for religious-cultural reasons. The sources of these sketch maps can be topographical sheets and air photos at scales of 1:10000 to 1:20000 for which there is often good coverage, especially of more settled agricultural areas. In addition to direct air photo interpretation by land-use planners, there is potential for utilizing local knowledge more fully. Experience with fieldwork in Tanzania has found that air photos are easily comprehended and interpreted by local farmers. As such, they can be used for rapid approximate delineation of village boundaries and of physical land units, and for the initial identification of environmental and socio-political problem zones.

\section{Summarizing information on distance-related problems at village and/or household scales}

To bring the extent and relative size of the distance problems to the attention of resource or agricultural planners, 'desire-line' sketches showing travel distances and frequency of trips can be made for representative household situations (Figs 1 and 2). The specific direction is usually not so significant, but arrows can be drawn proportional to travel distance, or to travel distance times number of trips per week. For greater detail these diagrams could be prepared for each peak season.

Frequency arrays should be drawn to show seasonal variation in the main agricultural activities (Figs 3,4). Figure 3 gives a hypothetical example showing the seasonal variations in labour requirements for field crop activities, not including those activities performed at home or on home plots. Such arrays illustrate movement requirements through the year, and in conjunction with 'average' distances and sizes of main crop plots, give a rough indication of seasonal journeys and effort. Labour 


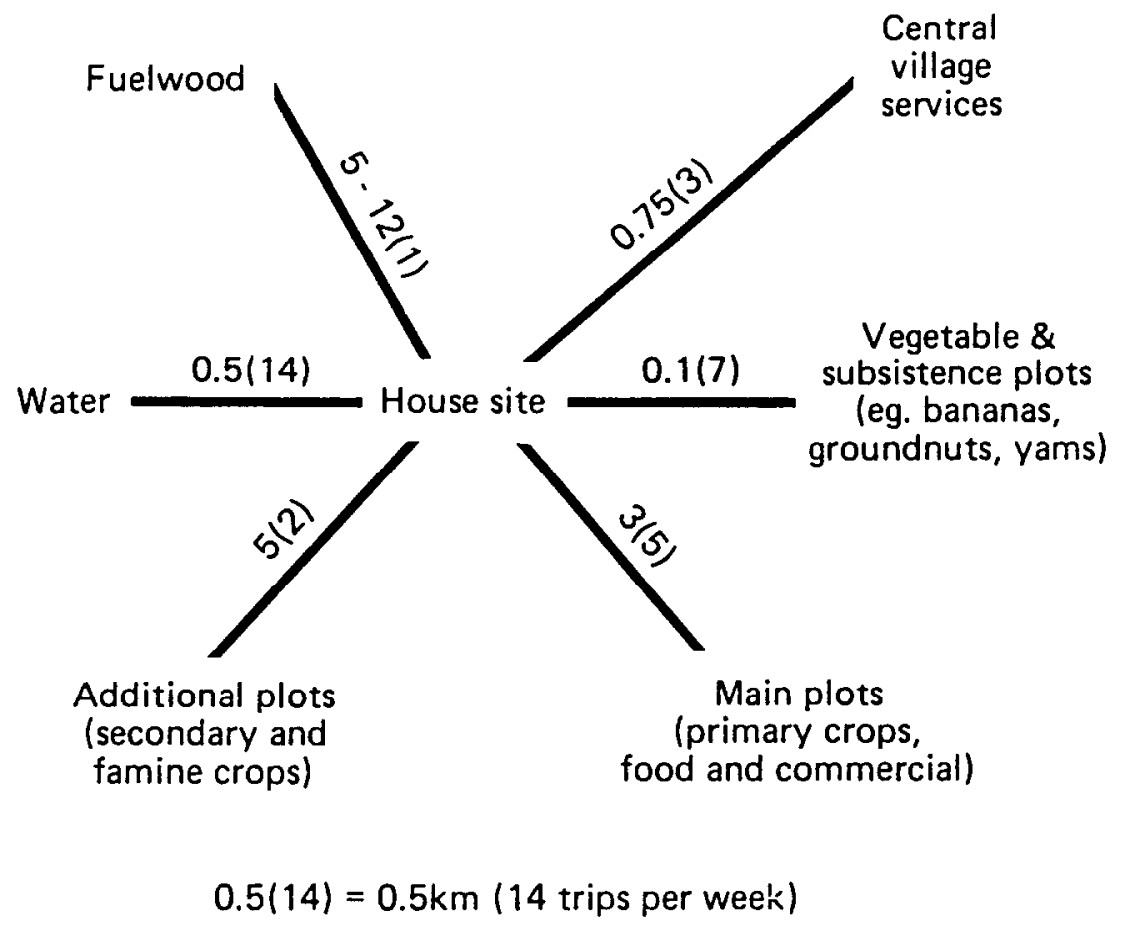

Figure 1. 'Desire lines'-journey to work for an agricultural household (rain-fed semisubsistence grains).

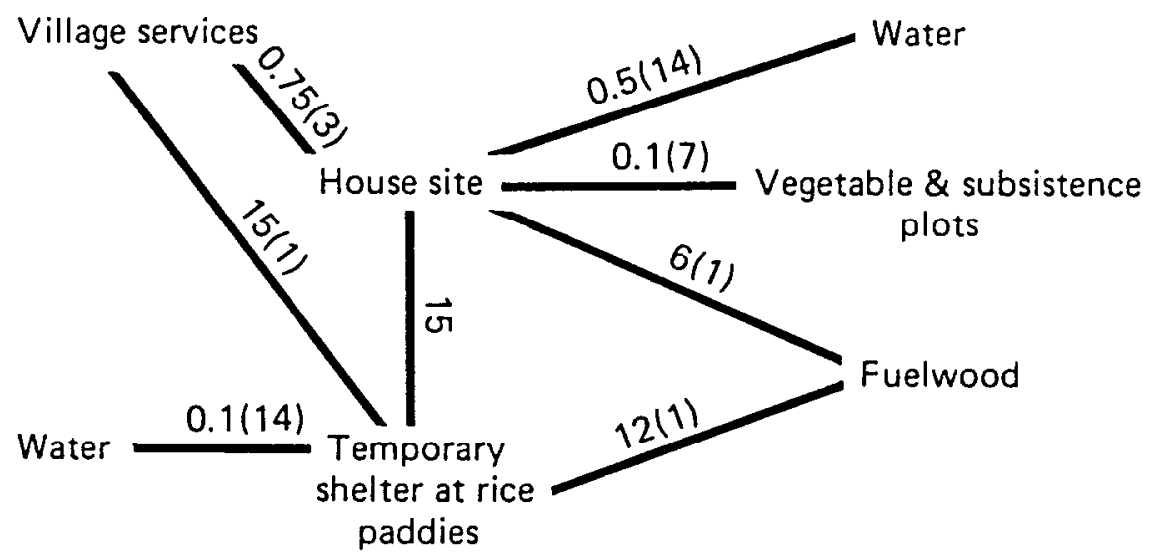

Figure 2. 'Desire lines'-journey to work for an agricultural household (naturally irrigated rice). 


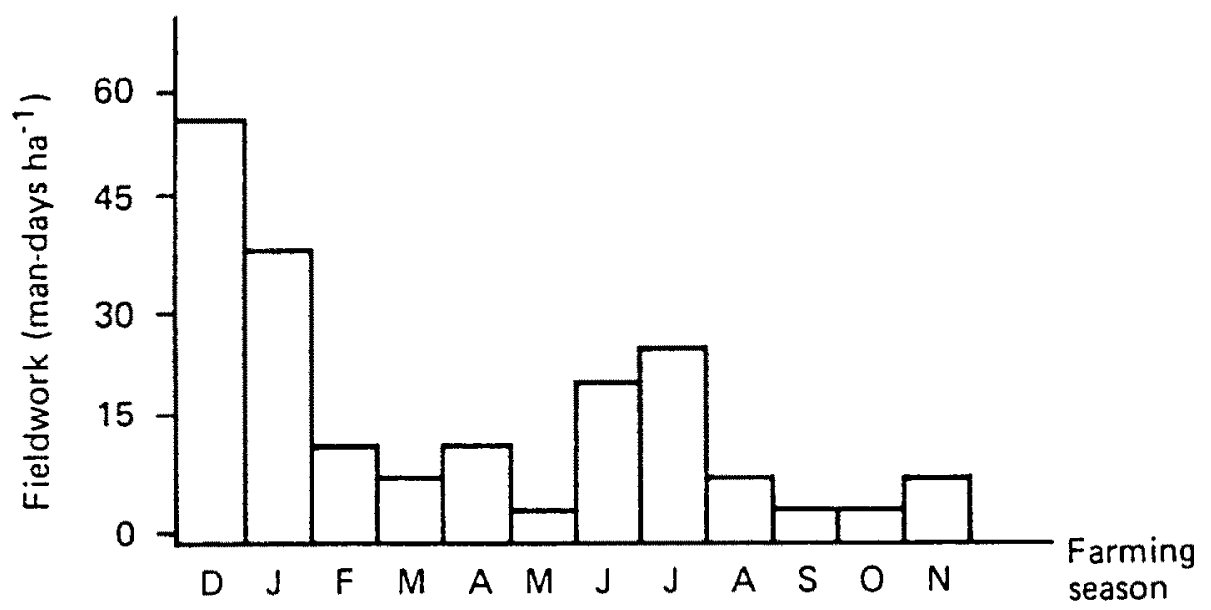

Figure 3. Monthly field labour requirements.

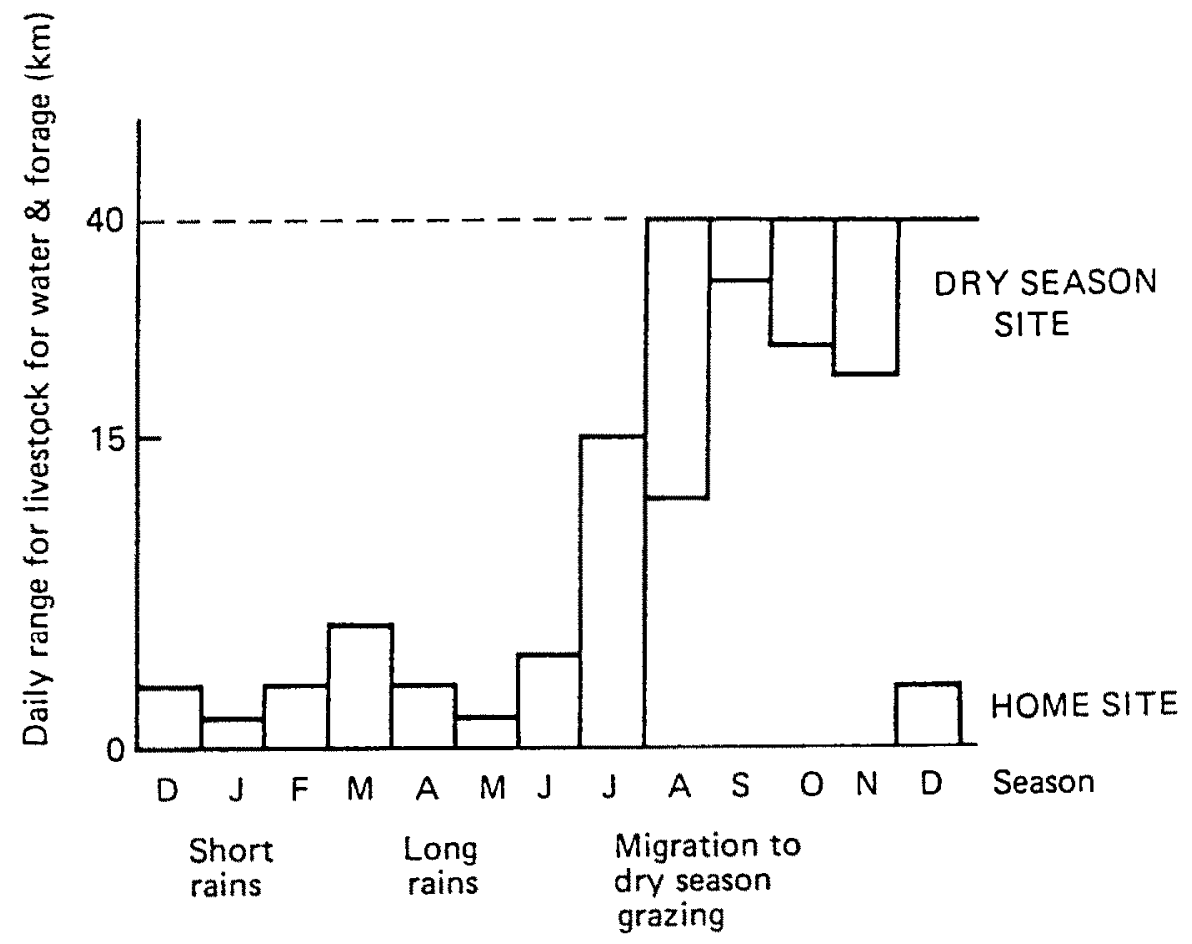

Figure 4. Monthly pastoral movements. 
input summaries are common in farming systems research, though they can only be approximations which exclude scale economies.

Time-space diagrams can be drawn to show local diurnal movement requirements, which Carlstein (1982) calls the 'daily round' of activities, and of which he provides many examples (Fig. 5). These are particularly useful to highlight the time-resource problems of women and female children, in absolute terms and relative to men; for example, the restrictions imposed on their fieldwork time because of water and fuelwood need, food preparation time and child care.

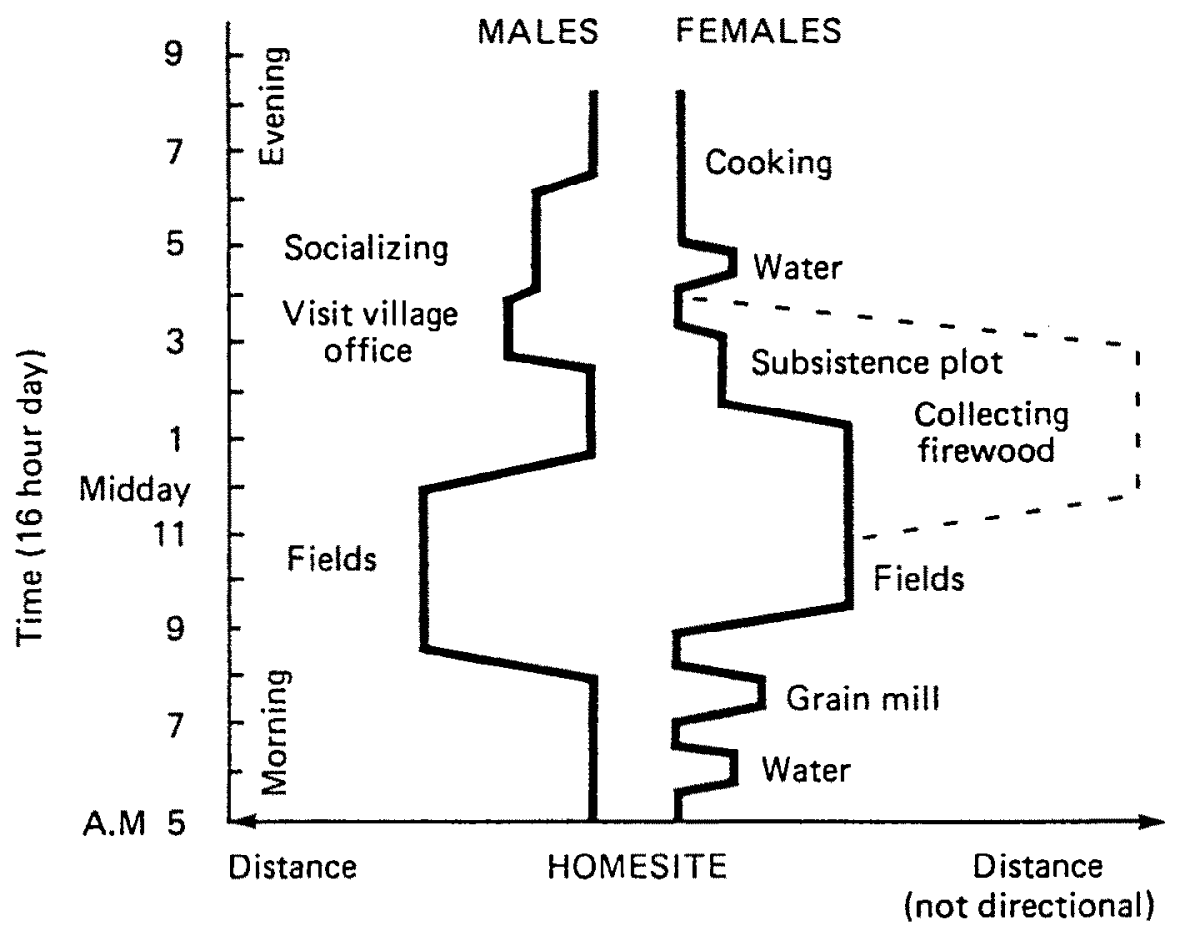

Figure 5. Time-space diagrams for local movement.

\section{Simple analyses of time-distance relationships}

Rapid calculations give the net time available for productive field labour, which can be called the 'effective working day' $(E w d)$. The $E w d$ is simply the field hours available after deducting necessary movement time; thus its calculation depends on the average speed of movement and thence on factors such as the transport mode, terrain, health and so on.

Depending on the survey resources available and accuracy desired, the "effective working day' at different locations can be represented spatially, either simply as distance annuli, or more accurately on village sketch maps showing the actual routeways and any specific restrictions on accessibility. For example, fairly crude measures have been used in village viability assessment studies in Tanzania to delimit areas easily available for cultivation $(5-\mathrm{km}$ radius), and for grazing $(7 \mathrm{~km})$, within legal village boundaries (Belshaw 1981). In an earlier review, Morgan (1969) found limiting distances for farming in tropical Africa empirically to be $6-11 \mathrm{~km}$. 
Assuming a generous eight-hour day and a brisk $5 \mathrm{~km} \mathrm{hr}^{-1}$, the loss in field hours can be shown as follows:

Distance:

Reduction in working day:

$4 \mathrm{~km} \quad 5 \mathrm{~km} \quad 6 \mathrm{~km} \quad 10 \mathrm{~km}$

$20 \% \quad 25 \% \quad 30 \% \quad 50 \%$

From a number of tropical African surveys (including earlier periods when population densities were much lower), it can be seen that travelling to and from fields took up to 50 per cent of the average working day. Surveys in northern Nigeria showed the highest figures-up to seven hours walking to/from fields. Several of these studies are summarized in Cleave (1974), and some others in Jackson (1972); whilst Chisholm (1979) in his review, concluded that on average, travelling took up 10 to 33 per cent of agricultural time (see also Carlstein 1982). The constraints on women's work are compounded in that the time required for the subsistence activities of water and fuelwood, walking time plus collection time, are part of women's effective working day (and sometimes also for men).

\section{Identifying potential solutions to the agro-economic problems of excessive distances}

In planning for rural improvements the next steps would be to analyse the information on daily and seasonal travel patterns (to and from fields, resources, services, etc.) and to evaluate potential solutions to the distance problems.

Analysis involves integrating the totality of travel needs data into methodologies which are already, or can be, developed for examining the constraints in peasant agricultural systems and assessing pertinent solutions. There is certainly scope for incorporating distance factors more explicitly into, for instance, FS research methodology (e.g. Byerlee et al. 1980; Norman et al. 1982) and into 'village viability assessment' (e.g. Belshaw 1981; McCall 1983; Corker 1983), both relatively comprehensive approaches to modelling farming constraints, allocating land uses and identifying improvements. There is also scope for emphasizing distance aspects in more specific planning tasks, such as in farm management, in estimating total labour requirements, infrastructure planning, or pasture improvement, for example.

The mode of integrating the distance factor is specific to each methodology, so will not be discussed further here. Potential solutions to the distance problem, however, deserve some consideration. It is instructive to outline the common, quotidian adjustments to excessive distances and to review very briefly the advantages, weaknesses and feasibility of potential planning solutions.

The 'distance problem' can be set in terms of the generalized carrying capacity, or viability of an area to support its population. Carrying capacity problems usually imply that there is insufficient land to support the population (and any livestock) with subsistence food, water, fuel, cash income, or services. But the basic argument above centres on 'sufficiency of land which is accessible within limited labour-time constraints'. Village or zonal carying capacity therefore must also include the criterion of "sufficient available and suitable land within "easy" access of residential sites'.

Where the main problem is access to farming land, the kinds of solutions which emerge either alter the farming system, or change the spatial structure.

\section{Changes in the organization of production}

1. Intensification of production ought to raise yields and so reduce the subsistence and cash-crop area requirements. Apart from the extra labour efforts, however, 
intensification needs a reliable supply of modern inputs and producer price incentives to compensate for purchased inputs. Moreover, 'modern' varieties and monocropping are more risky to small farmers because of greater vulnerability to ecological conditions.

2. Communal production sometimes encouraged in countries such as Mozambique, Tanzania and Ethiopia might possibly raise yields, increase the utilization of land and labour resources, and provide scale economies. However, in practice communal farming has generally failed to match the productivity of private farming due to a combination of lack of incentives, lack of work discipline and poor organization.

3. Land reform and plot consolidation programmes also attempt to solve the general distance problem, and seek economies of scale at the same time. Apart from the socio-political constraints on land reform, however, the desire for heterogeneous quality of land holdings as an element in risk reduction must also be taken into account, for instance in areas of pronounced relief or significant soil catenas (cf. King and Burton 1982: 485-7).

\section{Changes in the spatial structure}

1. Home-to-field transport can be upgraded, either through better vehicles (e.g. barrows, pack animals, bicycles or carts) or improved routeways, and, combined with on-site storage, would expand the area accessible within the peasants' 'daily round'. Although there are an increasing number of designs for such vehicles (Hathway 1984), there are few widespread applications, mainly because of their relative cost and the lack of supporting infrastructure and services. The current predominance of headloading, which accounts for $80-90$ per cent of micro-scale goods movement, is unlikely to be much altered.

2. Seasonal field shelters for use during peak periods of pest-scaring or harvesting used to be a rational means of reducing movement needs (Chisholm 1979; Carlstein 1982). As the level of material well-being and 'quality of life' has risen, however, such a solution becomes more problematic. People become more reliant on the resources and services based in the primary settlements, where they have also invested in their permanent residences. In more developed areas, such as Yorubaland, the seasonal 'farm-villages' have themselves become self-contained settlements competing with the towns for the deglomerated farming population. Ojo (1973) points out how this adversely affects the efficient provision of services or of potential small industries. In less-developed areas where the seasonal shelters remain bare subsistence, their use deprives their occupants of village benefitseven of sufficient balanced diet-and disrupts family and social life in the village.

3. The density of villages, and thus access to resources, can be manipulated either by increasing central settlement density through reducing average house plot size and thus shrinking the village, making all the external fields closer; or alternatively by reducing settlement density by dispersing permanent house sites to allow farmers to be surrounded by their main plots, but thereby increasing the average distance to central services. (This would imply a return to the common pre-resettlement situation of scattered farms.)

4. A compromise spatial organization for less developed areas, intermediate to those above, is that of permanent satellite settlements away from the primary villages. Chisholm (1979: 111-14) portrays examples from Europe and the Pacific as well as from Nigeria, and in Tanzania permanent satellites are being implemented as planned solutions to the 'distance-to-fields' problem (McCall 1983). Satellite 
dwellers would live closer to their land but also retain most economic and social benefits of communal life, the biggest disbenefit being longer distances to schools. Overall though, work-, service- and leisure-related trips should decline. Investment in satellites initially could be minimal, but with rising standards of living they could gradually add more functions and become more self-contained (cf. Ojo 1973).

\section{Demographic solutions}

Outmigration from areas unable to provide land access for new generations has often been a solution in the past. 'Excess' populations-either young men as individuals, or including the immediate families-have moved to emptier areas with reasonable ecological potential. In tropical Africa such possibilities are increasingly limited though not yet unknown. Rural-urban migration of young men (less often of women) is much more common. This reduces immediate land pressures, but often causes a shortage of productive labour in the rural area and it certainly brings about socio-economic problems in the towns. Finally, there is the alternative of population growth control through family planning, which though practised traditionally in the past cannot solve the problem in the near term.

\section{Access to resources}

Where there are problems of access to domestic fuels-normally implying long walking distances to wood sources-there are other potential solutions:

1. using other fuels-in practice usually crop wastes or manure-otherwise employed on the crops;

2. using grasses and waste materials which have lower heat values and require more collecting time;

3. developing fuelwood plantations which use up land but should provide a sustained output, or agroforestry with crops, firewood and tree products as combined outputs;

4. designing improved stoves to reduce fuelwood needs, though this would only have a marginal effect.

In practice fuelwood plantations and agroforestry are developing very slowly in tropical Africa because of technical, administrative, socio-political and basic resource deficiencies. Under these conditions, the most common response is simply to reduce domestic fuel use through less space heating, hygiene or cooking (Hoskins 1980; Moss and Morgan 1981).

Where there are further problems of access for livestock, additional responses are to stallfeed-which is labour-intensive and needs a broad biomass base-or to destock, which reduces aggregate demand for water and pasture but is socially and economically very difficult to implement and would have regressive effects against smaller herd owners (Toulmin 1983).

Where the focal problem is the inability to produce enough food a desirable solution would be intensification. More likely, however, is 'pseudo-intensification' involving growing starchy foods which are high yielding but low in proteins and vitamins, and which tends to exacerbate the social and nutritional problems caused by declining production of the primary foods (cf. Ruthenberg 1976; Carlstein 1982). On the other hand there are usually possibilities to (re-) develop non-crop food sources such as fish, forest products, insects and wild game. Where labour-market 
possibilities exist, peasants increasingly engage in wage labour (e.g. urban, plantation, services, or government work) in order to earn cash to purchase food. When local possibilities are scarce they may seasonally outmigrate for wage labour, or else open temporary farms in 'frontier zones' to grow cash crops as commodities and perhaps some food crops to send home.

\section{Conclusions}

The solutions to the distance problem which appear to hold the highest long term potential for development are agricultural intensification and/or permanent satellite settlements. However, there are difficulties with both as regards policy and implementation. Intensification faces severe economic hindrances as evidenced by its slow pace in African peasant farming due to problems of investment costs, price incentives and market development (see e.g. World Bank 1984). Satellites have considerable potential if infrastructure and housing costs are not too high, and where the savings in the journeys to fields outweigh the difficulties in providing access to central services. For the immediate future, as productivity declines on accessible land, the distance problem will only deteriorate in most areas, and in practice will be overcome only by longer walking times or some improved means of transport. Even though the journey to work in agriculture is clearly not independent of other farming systems problems, it is a mistake not to appreciate its broad significance.

\section{Acknowledgements}

I should like to acknowledge the helpful comments on an earlier draft by Dr John Briggs and several anonymous reviewers for Applied Geography. The remaining peculiarities are my own.

\section{References}

Belshaw, D. G. R. (1981) Village viability assessment procedures in Tanzania: decision-making with curtailed information requirements. Public Administration and Development 1 (1), $3-13$.

Beneria, L. (1982) Accounting for women's work. In Women and development: the sexual division of labour in rural societies (L. Beneria, ed.), Ch. 5. New York: Praeger for ILO.

Blumberg, R. L. (1981) Rural women in development. In Women and world change (N. Black and A. B. Cottrell, eds), pp. 32-56. Beverly Hills: Sage.

Byerlee, D., Collinson, M. et al. (1980) Planning technologies appropriate to farmers: concepts and procedures. Mexico City: CIMMYT (Centro Internacional de Mejoramiento de Maiz y Trigo), Economics Program.

Carlstein, T. (1982) Time resources, society and ecology. Lund: Lund Studies in Geography, Series B, No. 49.

Carr, M. (1983) The long walk home. Appropriate Technology 10 (1), 17-19.

Cecelski, E. (1984) The rural energy crisis, women's work and family welfare: perspectives and approaches to action. Geneva: ILO, World Employment Programme Research, Working Paper WEP 10/WP 35.

Chisholm, M. C. (1979) Rural settlement and land use, 3rd ed. London: Hutchinson.

Cleave, J. (1974) African farmers: lahor use in the development of smallholder agriculture. New York: Praeger.

Collinson, M. P. (1982) Farming systems research in eastern Africa: the experience of CIMMYT and some national agricultural research services, 1976-81. East Lansing: Michigan State University, Department of Agricultural Economics, MSU International Development Paper No. 3, 
Corker, I. R. (1983) Tabora Integrated Development Project, Land Use Component, Land Use Planning Handbook. Surbiton: Land Resources Development Centre, Project Record 66 (TANZA-05-37/REC-66/83).

Doyle, C. (1974) Productivity, technical change and the peasant producer: a profile of the African cultivator. Food Research Institute Studies 13, 61-76.

Ellis, F. (1981) A preliminary analysis of the decline in Tanzanian cashewnut production, 1974-79. Norwich: University of East Anglia, School of Development Studies, Discussion Paper No. 88.

Hahn, N. D. (1982) Women's access to land. Land Reform, Land Settlement and Cooperatives, No. $1 / 2,1-11$.

Hathway, G. (1984) Low-cost vehicles: options for moving people and goods. London: Intermediate Technology Development Group.

Hedlund, H. and Lundahl, M. (1984) The economic role of beer in rural Zambia. Human Organisation 43 (1), 61-65.

Hoskins, M. (1980) Community forestry depends on women. Unasylva 32 (130), 27-32.

ICRAF (1983) Guidelines for agroforestry diagnosis and design. Nairobi: ICRAF (International Council for Research in Agroforestry), Working Paper No. 6.

Jackson, R. T. (1970) Some observations on the von Thünen method of analysis with reference to Southern Ethiopia. East African Geographical Review 8, 39-46.

Jackson, R. T. (1972) A vicious circle?-the consequences of von Thünen in tropical Africa. Area 4, 258-261.

Kamuzora, C. L. (1984) High fertility and the demand for labour in peasant economies: case of Bukoba District, Tanzania. Development and Change 15 (1), 105-124.

King, R. and Burton, S. (1982) Land fragmentation: notes on a fundamental rural spatial problem. Progress in Human Geography 6 (4), 475-494.

McCall, M. K. (1983) Environmental and agricultural impacts of Tanzania's villagisation programme. Enschede: Twente University of Technology, Technology and Development Group, Working Paper No. 6. Also in J. Clarke and L. Kosinski (eds) Population and development projects in Africa, Ch. 9. Cambridge: Cambridge University Press (in press).

McCall, M. K. (1985) More burdens but less weight: impacts of villagisation on women in Tanzania. Enschede: Twente University, Technology and Development Group, Working Paper No. 18.

Monod, T. (ed.) (1975) Pastoralism in tropical Africa. (Papers of the 13th International African Seminar, Niamey, 1972.) Oxford: Oxford University Press.

Morgan, W. B. (1969) The zoning of land use around rural settlements in tropical Africa. In Environment and land use in Africa (M. F. Thomas and A. W. Whittington, eds), pp. 301-319. London: Methuen.

Moss, R. P. and Morgan, W. B. (1981) Fuelwood and rural energy production and supply in the humid tropics. Dublin: Tycooly.

Norman, D. W., Simmons, E. and Hays, H. (1982) Farming systems in the Nigerian savanna: research and strategies for development. Boulder: Westview.

Ojo, G. J. A. (1973) Journey to agricultural work in Yorubaland. Annals of the Association of American Geographers 63 (1), 85-96.

O'Keefe, P. and Wisner, B. (eds) (1977) Land use and development. London: International African Institute, African Environment Special Report 5.

Raintree, J. B. (1984) A diagnostic approach to agroforestry design. In Strategies and designs for afforestation, reforestation and tree planting (K. F. Wiersum, ed.), pp. 252-273. Wageningen: Pudoc.

Ruthenberg, H. (1976) Farming systems in the tropics. Oxford: Clarendon.

Saul, M. (1981) Beer, sorghum and women-production for the market in rural Upper Volta. Africa 51 (3), 746-764.

Shapiro, K. H. (1982/3) Efficiency differentials in peasant agriculture and their implications for development policies. Journal of Development Studies 19 (2), 179-190.

Tadesse, Z. (1982) The impact of land reform on women: the case of Ethiopia. In Women and development: the sexual division of labor in rural societies (L. Beneria, ed.), pp. 203-222. New York: Praeger for ILO. 
Tindituuza, R. and Kateete, B. (1971) Essays on land fragmentation in Kigezi District. Kampala: Makerere University, Department of Geography, Occasional Paper No. 22.

Tinker, I. (1980) Household energy and rural women. Paper quoted in Ganapathy, R. S. (1983) The political economy of rural energy planning in the Third World. Review of Radical Political Economy 15 (3), 83-95.

Toulmin, C. (1983) Economic behaviour among livestock-keeping peoples: a review of the literature on the economics of pastoral production in the semi-arid zones of Africa. Norwich: University of East Anglia, School of Development Studies, Occasional Paper No. 25.

Vink, A. P. A. (1983) Landscape, ecology and land use. London: Longman.

World Bank (1984) Towards sustained development in sub-Saharan African: a joint program of action. Washington, D.C.: World Bank.

Young, A. and Goldsmith, P. F. (1977) Soil survey and land evaluation in tropical countries: Malawi. Geographical Journal 143 (3), 407-431.

(Revised manuscript received 20 May 1985) 